CARVALHO, A.M.; JUNQUEIRA, A.M.R.; VIEIRA, J.V.; REIS, A.; SILVA, J.B.C. Produtividade, florescimento prematuro e queima-das-folhas em cenoura cultivada em sistema orgânico e convencional. Horticultura Brasileira, Brasília, v.23, n.2, p.250-254, abr-jun 2005.

\title{
Produtividade, florescimento prematuro e queima-das-folhas em cenoura cultivada em sistema orgânico e convencional ${ }^{1}$
}

\author{
Assis M. Carvalho ${ }^{2}$; Ana Maria R. Junqueira ${ }^{3}$; Jairo V. Vieira² ${ }^{2}$ Ailton Reis²; João Bosco C. e Silva ${ }^{2}$ \\ ${ }^{2}$ Embrapa Hortaliças, C. Postal 218, 70359-970 Brasília-DF; ${ }^{3}$ UnB, C. Postal 4.508, 70910-970 Brasília-DF.
}

\begin{abstract}
RESUMO
Quatro ensaios foram implantados no verão para avaliar a produtividade, o florescimento prematuro e a queima-das-folhas em genótipos de cenoura conduzidos em sistema orgânico e convencional. Os ensaios foram instalados em Brazlândia e na Embrapa Hortaliças. O delineamento experimental foi de blocos ao acaso, com oito tratamentos (genótipos Alvorada, Brasília RL, Brasília Bionatur, Kuronan, Nantes 3 Tip Top, Carandaí AG 106, Brazlândia e Pop. 0212246) e cinco repetições. Os nutrientes foram incorporados ao solo através de composto orgânico, no sistema orgânico e, fertilizantes químicos, no sistema convencional. Aos 70 dias da semeadura as plantas foram avaliadas no campo para incidência de doenças. Foi também identificada a prevalência de patógenos. A colheita foi realizada 95 dias após a semeadura. O florescimento prematuro foi mais freqüente no genótipo Brasília Bionatur, no sistema convencional, em Brazlândia. Foi observada diferença entre genótipos para queima-das-folhas nos dois sistemas. Nantes foi a mais suscetível, enquanto a Pop. 0212246 foi uma das mais resistentes nos dois sistemas de cultivo. Alternaria dauci prevaleceu em Brazlândia, enquanto Cercospora carotae foi observado em ambas as localidades, no sistema orgânico. Quanto à produção comercial e total os genótipos Pop. 0212246 e Brazlândia estiveram entre os mais produtivos, independente do sistema de cultivo. Para produtividade comercial e total, número e peso de raízes refugadas o sistema convencional apresentou resultados superiores ao orgânico. As cultivares Brasília RL, Brazlândia e a Pop. 0212246 podem ser recomendadas para plantio no período de verão, no DF, independente do sistema de cultivo. A Pop. 0212246 apresenta características agronômicas desejadas pelo mercado e poderá futuramente ser disponibilizada para produtores da região.
\end{abstract}

Palavras-chave: Daucus carota L., Alternaria dauci, Cercospora carotae, resistência a doenças, produtividade, sistemas de cultivo.

\begin{abstract}
Yield, bolting and leaf blight in carrots grown under organic and conventional conditions
\end{abstract}

Four experiments were carried out with carrots genotypes during summer season in Distrito Federal, Brazil, to evaluate yield, bolting and leaf blight under organic and conventional conditions. The experiments were carried out in two locations and in each one two experiments were established, considering both crop systems. The experimental design was a random block with eight treatments and five replicates. The treatments consisted of the cvs. Alvorada, Brasília RL, Brasília Bionatur, Kuronan, Nantes 3 Tip Top, Carandaí AG 106, Brazlândia and Pop. 0212246. The soil was fertilized with organic compost for the organic trial and with chemical fertilizer for the conventional trial. Plants were evaluated for leaf blight incidence, 70 days after sowing date, through visual observation. Roots were harvested 95 days after sowing, washed, classified and weighted. Bolting was more frequent in Brasília Bionatur, under conventional condition, in Brazlândia. A difference of susceptibility to leaf blight among genotypes was observed in plants cultivated in the organic system. Nantes was the most susceptible while Pop. 0212246 was the most resistant. Alternaria dauci was observed more frequently at Brazlândia, while Cercospora carotae was observed at both locations, similarly, under organic conditions. For commercial and total yield, commercial and total root number, Pop. 0212246 and Brazlândia were the best materials in both crop systems. Total and commercial yield, total and commercial root number, number and weight of refused roots were higher in the conventional area, compared to the organic area. Brasília and Brazlândia can be recommended for Distrito Federal, independently of crop system, during summer season. Pop. 0212246 showed desirable agronomical characteristics and can be, in the future, available for farmers in Distrito Federal.

Keywords: Daucus carota L., Alternaria dauci, Cercospora carotae, disease resistance, commercial yield, crop systems.

(Recebido para publicação em 9 de março de 2004 e aceito em 7 de abril de 2005)

\begin{abstract}
A cenoura é muito sensível às condições ambientais, o que determina a recomendação do genótipo de acordo com o local e época de cultivo. As cultivares importadas são recomendadas para o plantio de outono-inverno devido a pouca sensibilidade ao florescimento precoce. No verão, elas apresentam alta suscetibilidade à queima-das-folhas, doença favorecida por

condições de alta umidade e temperatura. As cultivares nacionais são recomendadas para o cultivo de verão por apresentarem boa resistência à queima-dasfolhas e ao florescimento prematuro. $\mathrm{O}$ florescimento prematuro é mais freqüente sob condições de baixa temperatura e fotoperíodo crescente, mais comuns no período de inverno-primavera (CARDOSO; DELLA VECCHIA, 1995).
\end{abstract}

Pessoa e Cordeiro (1997), avaliando cinco genótipos de cenoura no outono-inverno, no campo experimental da Embrapa Hortaliças, concluíram que a cv. Tropical foi a mais suscetível ao florescimento prematuro. Os genótipos Pop. F9, Kuronan e Brasília não diferiram entre si e foram resistentes ao florescimento prematuro. $\mathrm{Cv}$. Nantes não apresentou plantas florescidas e não diferiu de 'Brasília'.

\footnotetext{
${ }^{1}$ Trabalho realizado como parte da dissertação de mestrado do primeiro autor
} 
A queima-das-folhas, principal doença da cenoura é causada pelos patógenos Alternaria dauci (Kuhn) Groves \& Skolko, Cercospora carotae (Pass) Solheim e Xanthomonas campestris pv. carotae (Kendrick) Dye. Os três patógenos podem estar presentes isoladamente, ou ao mesmo tempo, e causar sintomas semelhantes (REIFSCHNEIDER, 1980). A doença afeta a parte aérea, reduzindo a produção e a qualidade, principalmente nos plantios de verão, sob condições de alta umidade (HENZ; LOPES, 2000). Em cultivos orgânicos, como não é permitido o uso de agrotóxicos, exceto algumas caldas à base de cobre, extratos e óleos essenciais de plantas, o controle da doença torna-se dependente da resistência genética das plantas e do manejo do cultivo.

Em avaliação feita no período de verão em Uberlândia, Juliatti et al. (1996) concluíram que a severidade da queima-das-folhas apresentou alta correlação negativa $(-0,77)$ com o peso de raízes comerciais.

Para o sucesso no cultivo da cenoura é essencial a escolha de cultivares que atendam a exigência do mercado quanto à qualidade das raízes, tolerância a temperaturas e resistência às principais doenças. $\mathrm{O}$ consumidor brasileiro, principalmente dos grandes centros, prefere cenouras que apresentam formato cilíndrico, lisas, bem desenvolvidas, ausência de raízes laterais, com diâmetro de $3,5 \mathrm{~cm}$, comprimento de $15-20 \mathrm{~cm}$, coloração alaranjada intensa, sem ombro e pigmentação verde ou roxa na parte superior (VIEIRA; PESSOA, 1997).

Souza (1996) observou produtividade de cenoura $7 \%$ superior no sistema de cultivo orgânico em relação ao convencional, em estudos realizados durante dez anos. Foram comparadas as produtividades observadas em uma estação de pesquisa com a observada em uma área particular, de cultivo comercial, no Espírito Santo. Segundo o autor, devido à falta de informações sobre cultivares para sistemas alternativos de produção, os produtores utilizam cultivares de cenouras desenvolvidas para o sistema convencional.

Sediyama et al. (1996), avaliando a cv. Brasília fertilizada com composto, bagaço-de-cana, capim napier ou palha de café e dejetos de suínos (líquido ou seco), além de fertilizantes químicos, concluíram que as maiores produções de raízes total, comercial e extra foram obtidas quando se utilizou o composto produzido com palha de café e dejetos líquidos de suíno. Souza (1996), comparando a aplicação de composto a lanço e no sulco de plantio, observou que a aplicação no sulco permitiu uma produtividade 39\% superior à obtida com aplicação a lanço.

Este trabalho teve como objetivo avaliar o florescimento prematuro, a severidade da queima-das-folhas e os agentes causais bem como a produtividade de raízes comerciais em oito genótipos de cenoura, conduzidos sob dois sistemas de cultivo, orgânico e convencional, em duas localidades, durante os meses de verão no DF.

\section{MATERIAL E MÉTODOS}

Os ensaios foram conduzidos em duas localidades de Brasília. Em Brazlândia foram instalados na Associação Mokiti Okada (MOA) e em área de produção convencional. Na Embrapa Hortaliças foram utilizados o campo experimental do programa de melhoramento da cenoura e a área destinada à Agricultura Orgânica. Os ensaios foram conduzidos de 20/11/2002 a 25/02/2003. A Embrapa Hortaliças está localizada a uma altitude de 998 m e Brazlândia a $1.100 \mathrm{~m}$.

As sementes utilizadas nos ensaios foram adquiridas no mercado local de Brasília e da empresa Bionatur em Candiota (RS). Foi utilizada uma linhagem do programa de melhoramento de cenoura da Embrapa Hortaliças com cinco ciclos de seleção. Todas as sementes foram oriundas do mesmo lote. O delineamento experimental utilizado foi de blocos ao acaso, com oito tratamentos e cinco repetições. As dimensões dos canteiros foram $24 \mathrm{x} 1,0 \mathrm{~m}$ e $20 \mathrm{~cm}$ de altura, espaçados de $0,40 \mathrm{~m}$ entre si.

No sistema convencional, a adubação foi realizada pelos resultados da análise de solo, conforme recomendação da Emater-DF/Embrapa Hortaliças. Em Brazlândia foram aplicados 1 t.ha $^{-1}$ de 04-30-16 e 10 t.ha ${ }^{-1}$ de cama de frango no plantio e, posteriormente, 500 kg.ha-1 de 10-10-10, duas pulverizações foliares de B e uma de Ca. Na Embrapa Hortaliças foram aplicados $500 \mathrm{~kg} \cdot \mathrm{ha}^{-1}$ de 04-30-16 no plantio.

No sistema orgânico, os nutrientes foram fornecidos por meio de compostos orgânicos que diferiram na quantidade, forma de aplicação, material de origem e forma de preparo. Na Associação Mokiti Okada (MOA) foram utilizados como matéria-prima: bagaço de cana-de-açúcar, farelo de mamona, farelo de arroz, resíduos de leguminosa e terra de barranco na quantidade de 40 t.ha ${ }^{-1}$ antes do plantio. Na Embrapa Hortaliças foram aplicadas 30 t.ha $^{-1}$ de composto, sendo $2 / 3$ no plantio e o restante em cobertura, o composto foi constituído de capim Panicum maximum triturado, capim Brachiara decumbens roçado e cama de matrizes de aves.

As sementes foram distribuídas manualmente, em linhas espaçadas de 0,20 $\mathrm{m}$, em sentido transversal ao comprimento do canteiro. A parcela foi constituída de 15 linhas de cenoura em 3,0 m² e área útil de $1,0 \mathrm{~m}^{2}$. A emergência das plântulas ocorreu após uma semana da semeadura. O controle das plantas daninhas, no sistema convencional, foi realizado com herbicida pré-emergente e, no sistema orgânico, com capina e arranquio manual. A água foi aplicada via sistema de irrigação por aspersão em ambas as localidades. O desbaste foi realizado 25-30 dias após a semeadura, deixando uma planta a cada $4-5 \mathrm{~cm}$ (VIEIRA, 1997).

A avaliação da queima-das-folhas foi realizada aos 70 dias após a semeadura. Foi adotada a escala subjetiva adaptada de Aguillar et al. (1986), onde $1=$ folhagem totalmente morta; 2 = folhas inferiores mortas, muitas lesões nas folhas superiores; $3=$ muitas lesões nas folhas inferiores, poucas lesões nas folhas superiores; $4=$ poucas lesões nas folhas inferiores, folhas superiores sadias e $5=$ folhagem totalmente sadia.

Avaliou-se a prevalência de patógenos associados às plantas doentes, nos dois locais e nos dois sistemas de cultivo. Para isso, foram coletadas ao acaso, em cada parcela, cinco folhas com manchas que permaneceram em câmara úmida por 24 horas. Em seguida, foram escolhidas três folhas e, de 
Tabela 1. Florescimento prematuro de genótipos de cenoura $\left(n^{\circ}\right.$ de plantas ha $\left.{ }^{-1}\right)$ cultivados nos sistemas orgânico e convencional, no verão do Distrito Federal ${ }^{1,2}$. Brasília, Embrapa Hortaliças, 2003.

\begin{tabular}{|c|c|c|c|c|c|c|}
\hline \multirow{2}{*}{ Genótipos } & \multicolumn{2}{|c|}{ Orgânico } & \multicolumn{2}{|c|}{ Convencional } & \multicolumn{2}{|c|}{ Sistemas } \\
\hline & Brazlândia & Embrapa & Brazlândia & Embrapa & Orgânico $^{3}$ & Convenciona \\
\hline Alvorada & $1.000 \mathrm{~b}$ & $1.146 a$ & $1.629 \mathrm{~cd}$ & $1.345 \mathrm{a}$ & $1.073 a b$ & $1.487 \mathrm{~cd}$ \\
\hline Brasília RL & $1.082 \mathrm{ab}$ & $1.082 \mathrm{a}$ & $1.712 \mathrm{c}$ & $1.982 \mathrm{a}$ & $1.082 \mathrm{ab}$ & $1.847 \mathrm{bc}$ \\
\hline Brasília Bionatur & $1.375 \mathrm{a}$ & $1.282 \mathrm{a}$ & $3.027 \mathrm{a}$ & $1.884 \mathrm{a}$ & $1.329 \mathrm{a}$ & $2.455 \mathrm{a}$ \\
\hline Kuronan & $1.000 \mathrm{~b}$ & $1.229 \mathrm{a}$ & $2.094 \mathrm{bc}$ & $1.082 \mathrm{a}$ & $1.114 a b$ & $1.588 \mathrm{~cd}$ \\
\hline Nantes 3 Tip Top & $1.000 \mathrm{~b}$ & $1.000 \mathrm{a}$ & $1.000 \mathrm{~d}$ & $1.146 \mathrm{a}$ & $1.000 \mathrm{~b}$ & $1.073 \mathrm{~d}$ \\
\hline Carandaí AG-106 & $1.082 a b$ & $1.165 \mathrm{a}$ & 1.829 bc & $1.192 \mathrm{a}$ & $1.124 a b$ & $1.561 \mathrm{~cd}$ \\
\hline Brazlândia & $1.165 a b$ & $1.229 \mathrm{a}$ & $2.374 \mathrm{~b}$ & $2.004 \mathrm{a}$ & $1.197 \mathrm{ab}$ & $2.189 a b$ \\
\hline Pop. 0212246 & $1.000 \mathrm{~b}$ & $1.082 \mathrm{a}$ & $1.522 \mathrm{~cd}$ & $1.165 \mathrm{a}$ & $1.041 \mathrm{ab}$ & $1.343 \mathrm{~cd}$ \\
\hline Média & $1.088 \mathrm{~A}$ & $1.152 \mathrm{~A}$ & $1.488 \mathrm{~B}$ & $1.898 \mathrm{~A}$ & $1.120 \mathrm{~B}$ & $1.693 \mathrm{~A}$ \\
\hline C.V. (\%) & 16,42 & 23,50 & 16,13 & 32,63 & 20,85 & 23,65 \\
\hline
\end{tabular}

${ }^{1}$ Médias seguidas pela mesma letra minúscula na coluna não diferem estatisticamente entre si, pelo teste de Tukey, ao nível de 5\% de probabilidade; ${ }^{2}$ Médias seguidas pela mesma letra maiúscula dentro de cada sistema e entre eles não diferem estatisticamente entre si, pelo teste de Tukey , a 5\% de probabilidade; ${ }^{3}$ Neste sistema houve interação entre genótipos e locais.

cada, foram retiradas cinco lesões para análise e identificação dos patógenos. Anotou-se a incidência de cada tipo de patógeno por folha (LOPES et al., 2000).

Foi realizada uma única colheita, aos 95 dias após o plantio, em cada ensaio. Manualmente, as raízes foram arrancadas, lavadas e classificadas pelo comprimento, diâmetro e defeitos, em comerciais e não comerciais e, posteriormente, pesadas. As plantas que apresentaram florescimento prematuro foram identificadas e pesadas. Para os dados de florescimento prematuro foi utilizada a transformação $\sqrt{x}+1$. Os dados foram submetidos à análise de variância e as médias comparadas pelo teste de Tukey, ao nível de 5\% de probabilidade.

\section{RESULTADOS E DISCUSSÃO}

\section{Florescimento Prematuro}

Em Brazlândia, independente do sistema de cultivo, foi observada diferença significativa entre genótipos para florescimento prematuro (Tabela 1), provavelmente pelo fato de Brazlândia localizar-se em um planalto de altitude (chapada, a $1.100 \mathrm{~m}$ ), sob ação constante dos ventos. No DF é comum ocorrerem temperaturas noturnas inferiores a $19^{\circ} \mathrm{C}$ durante o verão e isto pode ter contribuído para que o florescimento médio em Brazlândia tenha sido superior ao apresentado na Embrapa Hortaliças.

No sistema convencional, o florescimento médio dos genótipos foi superior ao observado nos genótipos conduzidos sob sistema orgânico (Tabela 1).
É possível que uma disponibilização de nutrientes solúveis em grandes quantidades possa ter causado algum tipo de desequilíbrio na planta (CHABOUSSOU, 1999), aumentando a taxa de florescimento prematuro. Esta taxa pode ser reduzida quando o solo possui maior nível de matéria orgânica. Os quelatos do solo liberam de forma lenta os nutrientes para as plantas. Este comportamento foi evidenciado no ensaio instalado na MOA. Nesta localidade o teor de matéria orgânica foi superior às demais.

O maior florescimento prematuro observado na cultivar Brasília Bionatur no sistema convencional, em relação à Brasília RL (Tabela 1), pode estar relacionado ao processo de produção de sementes. O método de produção semente-a-semente, adotado pela empresa Bionatur, pode ter influenciando negativamente na qualidade final da semente. A Embrapa Hortaliças utiliza o método raiz-a-raiz, onde é mantido o padrão genético da população original.

\section{Queima-das-folhas: Avaliação visual}

Para o sistema orgânico, nos dois locais, a cv. Nantes 3 foi a mais suscetível. Na Embrapa Hortaliças a Pop. 0212246 foi a mais resistente. No sistema convencional, em Brazlândia, a cv. Nantes destacou-se como a mais suscetível e a Pop. 0212246, Kuronan, Brazlândia e Carandaí como resistentes. $\mathrm{Na}$ Embrapa Hortaliças, as cv. Nantes 3, Brasília RL, Carandaí e Brazlândia, mostraram-se mais suscetíveis, enquanto que a Pop. 0212246, Kuronan,
Brasília Bionatur e Alvorada mostraram-se resistentes (Tabela 2).

Os genótipos implantados no sistema orgânico apresentaram nota média superior à do sistema convencional. Supõe-se que a utilização de agrotóxicos no sistema convencional provoque algum desequilíbrio na planta, que contribui para o aumento do número de patógenos (CHABOUSSOU, 1999). No sistema orgânico ocorreram interações entre genótipos e local, e a cv. Nantes 3 foi a mais suscetível à doença. No sistema convencional 'Nantes 3' mostrou-se suscetível, enquanto que a 'Pop. 0212246' e 'Kuronan' foram as mais resistentes (Tabela 2).

\section{Queima-das-folhas: Prevalência} de patógenos

No sistema orgânico, em Brazlândia, observou-se que Alternaria dauci e Cercospora carotae estiveram presentes em todos os genótipos. Neste local, destacou-se a cv. Nantes que apresentou 63 lesões de $A$. dauci de um total de 75 lesões observadas, evidenciando que esta cultivar foi mais suscetível à $A$. dauci do que à $C$. carotae. Na Embrapa Hortaliças A. dauci e C. carotae também estiveram presentes em todos os genótipos, sendo que $A$. dauci esteve presente com maior freqüência. A cv. Brazlândia apresentou 20 lesões não identificadas, ou seja, de etiologia diferente dos patógenos avaliados. Os demais genótipos apresentaram entre $40 \mathrm{e}$ 50 lesões de $A$. dauci, das 75 observadas. A cv. Brasília Bionatur apresentou o maior número de lesões (51) de $A$. dauci. 
Tabela 2. Valores médios de notas atribuídas a queima-das-folhas em genótipos de cenoura em avaliação visual, realizada aos 70 dias após a semeadura, nos sistemas de cultivo orgânico e convencional em dois locais, nos meses de verão, no Distrito Federal ${ }^{1,2}$. Brasília, Embrapa Hortaliças, 2003.

\begin{tabular}{|c|c|c|c|c|c|c|}
\hline \multirow{2}{*}{ Genótipos } & \multicolumn{2}{|c|}{ Orgânico } & \multicolumn{2}{|c|}{ Convencional } & \multicolumn{2}{|c|}{ Sistemas } \\
\hline & Brazlândia & Embrapa & Brazlândia & Embrapa & Orgânico $^{3}$ & Convencional \\
\hline Alvorada & $5,0 \mathrm{a}$ & $3,2 \mathrm{~b}$ & $3,8 \mathrm{bc}$ & $3,6 a b$ & $4,10 \mathrm{a}$ & $3,70 \mathrm{bc}$ \\
\hline Brasília RL & 5,0 a & $3,3 \mathrm{~b}$ & $3,0 \mathrm{c}$ & $3,0 \mathrm{bc}$ & $4,15 a$ & $3,00 \mathrm{c}$ \\
\hline Brasília B. & $4,8 \mathrm{a}$ & $3,6 \mathrm{~b}$ & $3,4 \mathrm{c}$ & $3,6 a b$ & $4,20 \mathrm{a}$ & $3,50 \mathrm{bc}$ \\
\hline Kuronan & $5,0 \mathrm{a}$ & $3,6 \mathrm{~b}$ & $4,6 a b$ & $3,7 \mathrm{ab}$ & $4,30 \mathrm{a}$ & $4,15 a b$ \\
\hline Nantes 3 & $3,2 \mathrm{~b}$ & $2,1 \mathrm{c}$ & $1,4 \mathrm{~d}$ & $2,3 \mathrm{c}$ & $2,65 \mathrm{~b}$ & $1,85 d$ \\
\hline Carandaí & $5,0 \mathrm{a}$ & $3,1 \mathrm{~b}$ & $4,0 a b c$ & $3,0 \mathrm{bc}$ & $4,05 \mathrm{a}$ & $3,50 \mathrm{bc}$ \\
\hline Brazlândia & $5,0 \mathrm{a}$ & $3,5 \mathrm{~b}$ & $4,0 \mathrm{abc}$ & $3,2 \mathrm{bc}$ & $4,25 \mathrm{a}$ & $3,60 \mathrm{bc}$ \\
\hline Pop. 0212246 & $5,0 \mathrm{a}$ & $4,3 \mathrm{a}$ & $5,0 \mathrm{a}$ & $4,6 \mathrm{a}$ & $4,65 \mathrm{a}$ & $4,8 \mathrm{a}$ \\
\hline Média & $4,75 \mathrm{~A}$ & $3,33 \mathrm{~B}$ & $3,65 \mathrm{~A}$ & $3,37 \mathrm{~A}$ & $4,04 \mathrm{~A}$ & $3,51 \mathrm{~B}$ \\
\hline C.V. (\%) & 4,62 & 9,01 & 13,74 & 16,14 & 20,53 & 17,85 \\
\hline
\end{tabular}

${ }^{1}$ Escala de notas, onde o grau 1 corresponde à folhagem totalmente morta e o grau 5 à folhagem sadia; ${ }^{2}$ Médias seguidas pela mesma letra na coluna não diferem estatisticamente entre si, pelo teste de Tukey, ao nível de $5 \%$ de probabilidade; ${ }^{3}$ Neste sistema houve interação entre genótipos e locais.

Para o sistema convencional, em Brazlândia, a A. dauci esteve presente em todas as lesões observadas, o que não ocorreu com $C$. carotae. Não ocorreram diferenças significativas entre genótipos para a prevalência de $A$. dauci. Entretanto, como ocorreram diferenças significativas entre os genótipos nas avaliações visuais realizadas no campo (Tabela 2) para queima-das-folhas, acredita-se que os genótipos apresentem respostas diferentes na presença do patógeno. Para prevalência de patógenos a cv. Nantes apresentou 75 lesões de $A$. dauci, e na escala visual de notas foi the conferida a nota 1,4 , evidenciando que essa cultivar apresenta maior suscetibilidade ao patógeno no campo que os demais materiais.

Já na Embrapa Hortaliças a A. dauci e $C$. carotae estiveram presentes em todos os genótipos, não sendo possível identificar quem foi mais prevalente no geral. Entretanto, a cv. Nantes apresentou 40 lesões de $A$. dauci e 15 de $C$. carotae reforçando a hipótese de que esta cultivar de cenoura seria mais suscetível ao primeiro destes patógenos.

Analisando o comportamento de $A$. dauci, em uma média de 150 lesões, para cada sistema de cultivo, verificou-se maior prevalência deste patógeno no sistema convencional. A cv. Nantes, em termos absolutos (55 lesões) apresentou maior prevalência do patógeno, em ambos os sistemas de cultivo. Os genótipos Pop. 0212246 e Alvorada, com média de 40 e 45 lesões, respectivamente, apresentaram uma menor prevalência de $A$.

Tabela 3. Produtividade de raízes comerciais e do total de raízes de oito genótipos de cenoura cultivados, em sistema orgânico e convencional, durante os meses de verão, no Distrito Federal' $^{1}$ Brasília, Embrapa Hortaliças, 2003.

\begin{tabular}{|c|c|c|c|c|}
\hline \multirow{2}{*}{ Genótipos } & \multicolumn{2}{|c|}{$\begin{array}{l}\text { Produtividade de raízes } \\
\text { comerciais }\left(\mathrm{kg}^{\left.-\mathrm{ha}^{-1}\right)}\right.\end{array}$} & \multicolumn{2}{|c|}{$\begin{array}{l}\text { Produtividade do total de } \\
\text { raízes }\left(\mathrm{kg} \cdot \mathrm{ha}^{-1}\right)\end{array}$} \\
\hline & Orgânico & Convencional & Orgânico & Convencional \\
\hline Alvorada & $10.631 \mathrm{c}$ & $17.712 \mathrm{bc}$ & $18.961 \mathrm{~b}$ & $26.403 \mathrm{bc}$ \\
\hline Brasília RL & $13.841 \mathrm{abc}$ & $14.250 \mathrm{bc}$ & $23.286 a b$ & $23.968 \mathrm{bc}$ \\
\hline Brasília Bionatur & $12.457 \mathrm{bc}$ & $15.718 \mathrm{bc}$ & $23.450 a b$ & 27.174 b \\
\hline Kuronan & $15.775 a b$ & $18.106 \mathrm{~b}$ & $22.808 a b$ & $27.706 b$ \\
\hline Nantes 3 Tip Top & $2.358 \mathrm{~d}$ & $643 d$ & $8.134 \mathrm{c}$ & $4.922 \mathrm{~d}$ \\
\hline Carandaí AG 106 & $12.341 \mathrm{bc}$ & $14.112 \mathrm{c}$ & $20.065 b$ & $22.800 \mathrm{c}$ \\
\hline Brazlândia & $16.617 \mathrm{ab}$ & 23.782 a & 26.029 a & $32.621 \mathrm{a}$ \\
\hline Pop. 0212246 & $17.561 \mathrm{a}$ & 24.992 a & $23.620 \mathrm{ab}$ & 33.766 a \\
\hline Média & $12.599 \mathrm{~B}$ & $16.164 \mathrm{~A}$ & 20.794 B & $24.930 \mathrm{~A}$ \\
\hline C.V. (\%) & 25,43 & 16,29 & 20,12 & 11,34 \\
\hline
\end{tabular}

${ }^{1}$ Médias seguidas pela mesma letra na coluna não diferem estatisticamente entre si, pelo teste de Tukey, ao nível de 5\% de probabilidade.

dauci, em ambos os sistemas de cultivo, evidenciando uma boa estabilidade em ambientes diferentes.

Para o sistema orgânico o patógeno C. carotae foi encontrado em Brazlândia com maior frequiência, variando de 10 a 43 lesões. Na Embrapa Hortaliças a freqüência deste patógeno variou de 14 a 29 lesões entre genótipos. Considerando as duas localidades, os genótipos Brazlândia (42 lesões), Carandaí (35 lesões), Pop.0212246 (29 lesões) e Brasília (25 lesões) apresentaram maior prevalência de $C$. carotae e a cv. Nantes (10 lesões) a menor.

No sistema convencional foi evidenciada uma maior diferença entre localidades em termos de prevalência de patógenos, pois em Brazlândia não se observou a presença de $C$. carotae. $\mathrm{Su}-$ põe-se que as constantes aplicações de fungicidas à base de cobre tenham sido mais eficientes contra este patógeno. Como na Embrapa Hortaliças não foram utilizados fungicidas, acredita-se que não tenha havido interferência na presença destes patógenos.

\section{Produtividade comercial e total de} raízes

Houve interação entre genótipos e localidade para os dois parâmetros avaliados. O sistema convencional apresentou produtividade média de raízes comerciais superior ao observado sob sistema orgânico. No sistema orgânico, a 
Tabela 4. Número de raízes refugadas $\left(\mathrm{ha}^{-1}\right)$ e peso de raízes refugadas $\left(\mathrm{kg} \mathrm{ha}^{-1}\right)$ de oito genótipos de cenoura, cultivados em sistema orgânico e convencional, durante os meses de verão, no Distrito Federal ${ }^{1}$. Brasília, Embrapa Hortaliças, 2003.

\begin{tabular}{lcccccc}
\hline \multirow{2}{*}{ Genótipos } & \multicolumn{2}{c}{ Número de raízes refugadas } & & \multicolumn{2}{c}{ Peso de raízes refugadas } \\
\cline { 2 - 3 } \cline { 7 - 8 } & \multicolumn{2}{c}{ Orgânico } & Convencional & & Orgânico & Convencional \\
\hline Alvorada & $212.480 \mathrm{c}$ & $276.160 \mathrm{~b}$ & & $8.329 \mathrm{abc}$ & $8.691 \mathrm{a}$ \\
Brasília RL & $282.880 \mathrm{abc}$ & $365.760 \mathrm{ab}$ & & $9.445 \mathrm{ab}$ & $9.718 \mathrm{a}$ \\
Brasília Bionatur & $305.280 \mathrm{ab}$ & $406.080 \mathrm{a}$ & & $10.982 \mathrm{a}$ & $11.456 \mathrm{a}$ \\
Kuronan & $238.720 \mathrm{bc}$ & $332.160 \mathrm{ab}$ & & $7.033 \mathrm{bc}$ & $9.600 \mathrm{a}$ \\
Nantes 3 Tip Top & $317.440 \mathrm{a}$ & $400.320 \mathrm{ab}$ & & $5.776 \mathrm{c}$ & $4.278 \mathrm{~b}$ \\
Carandaí AG 106 & $272.000 \mathrm{abc}$ & $340.800 \mathrm{ab}$ & & $7.723 \mathrm{bc}$ & $8.768 \mathrm{a}$ \\
Brazlândia & $284.800 \mathrm{abc}$ & $318.720 \mathrm{ab}$ & & $9.411 \mathrm{ab}$ & $8.838 \mathrm{a}$ \\
Pop. 0212246 & $225.600 \mathrm{bc}$ & $289.600 \mathrm{ab}$ & & $6.058 \mathrm{c}$ & $8.774 \mathrm{a}$ \\
\hline Média & $267.400 \mathrm{~B}$ & $341.200 \mathrm{~A}$ & & $8.095 \mathrm{~B}$ & $8.765 \mathrm{~A}$ \\
\hline C.V. (\%) & 21,55 & 27,00 & & 27,58 & 23,65 \\
\hline
\end{tabular}

${ }^{1}$ Médias seguidas pela mesma letra na coluna não diferem estatisticamente entre si, ao nível de $5 \%$ de probabilidade, pelo teste de Tukey.

cv. Nantes 3 foi a menos produtiva, enquanto que a Pop. 0212246, Brazlândia, Kuronan, e Brasília RL foram as mais produtivas. No sistema convencional a Pop. 0212246 e a cv. Brazlândia foram as mais produtivas, sendo que 'Nantes 3' apresentou a menor produtividade (Tabela 3 ). Acredita-se que a menor produtividade média de raízes comerciais observada no sistema orgânico tenha ocorrido em função do solo da área para produção orgânica da Embrapa Hortaliças estar ainda em processo de construção da fertilidade pela adição dos compostos orgânicos, adubos verdes e fosfatos naturais. Assim, a menor disponibilidade de nutrientes para as plantas pode ter contribuído para uma menor produtividade média de raízes comerciais.

No sistema convencional, a maior produtividade média de raízes comerciais deve ter ocorrido pela quantidade de fertilizantes, usualmente, aplicada pelo produtor em Brazlândia e pelo nível de nutrientes encontrado no solo, principalmente, de fósforo, potássio e cálcio.

Os genótipos Pop. 0212246 e Brazlândia mostraram-se promissores, na produção de raízes comerciais, independente do sistema de cultivo. O comprimento médio e o formato cilíndrico das raízes, aliados à resistência a doenças conferiram estabilidade na produtividade de raízes comerciais.

Para produção total de raízes no sistema orgânico, a cv. Nantes 3 foi a menos produtiva, enquanto que Brazlândia, Pop. 0212246, Brasília RL, Brasília
Bionatur e Kuronan apresentaram a cional, a Pop. 0212246 e a cv. Brazlândia foram as mais produtivas e a cv. Nantes a menos produtiva (Tabela 3).

Os genótipos que se destacaram na produtividade total de raízes mantiveram a mesma tendência para produtividade comercial. Ocorreu relação direta entre essas duas características, com pequenas variações entre genótipos e sistemas de produção. Para produtividade total, a média dos genótipos do sistema convencional foi superior a dos genótipos implantados no sistema orgânico, diferindo do observado por Souza (2001).

Número e peso de raízes refugadas

Para número de raízes refugadas ocorreram interações entre genótipos e localidade em ambos os sistemas. No orgânico, a cv. Nantes 3 diferiu apenas da Pop. 0212246, Alvorada e Kuronan, enquanto que no sistema convencional, Brasília Bionatur e Alvorada diferiram entre si. O sistema convencional apresentou uma média superior à observado no sistema orgânico (Tabela 4). O sistema convencional, por apresentar maior produtividade média e maior número de raízes totais, pode ter contribuído para um maior número de raízes refugadas.

Para peso de raízes refugadas, no sistema orgânico, não ocorreram interações entre genótipos e localidade. A cv. Brasília Bionatur apresentou o maior valor, sem diferir de Brasília RL, Brazlândia e da cv. Alvorada. No sistema convencional, somente a cv. Nantes 3 diferenciou-se dos demais genótipos, maior produtividade. No sistema conven- apresentando o menor valor.

Entre sistemas agrícolas, os genótipos conduzidos no sistema convencional apresentaram peso médio de raízes refugadas superior ao apresentado pelos genótipos no sistema orgânico. O genótipo Brasília Bionatur apresentou maior peso de raízes refugadas em ambos os sistemas agrícolas, embora não diferindo de Brasília RL (Tabela 4).

As cultivares Brasília RL, Brazlândia e a Pop. 0212246 apresentaram bom desempenho agronômico, no período de verão, no Distrito Federal, independente do sistema de cultivo.

\section{LITERATURA CITADA}

AGUILLAR, J.A.E.; REIFSCHNEIDER, F.J.B.; PESSOA, H.B.S.V. Época de início de aplicação de fungicidas para o controle de queima-das-folhas de cenoura, Horticultura Brasileira, Brasília, v.4, n.11, p.41, 1986.

CARDOSO, A.I.I.; DELLA VECCHIA, P.T. Considerações sobre o florescimento prematuro e suas aplicações para o melhoramento de cenoura para primavera. Horticultura Brasileira, Brasília, v.13, n.2, p.146-149, 1995.

CHABOUSSOU, F. As plantas doentes pelo uso de agrotóxicos: a teoria da trofobiose. Guazzeli, M.J. (trad.). $2^{\text {a }}$ ed. Porto Alegre, 1999. 272 p.

HENZ, G.P.; LOPES, C.A. Doenças das apiáceas. In: ZAMBOLIN, L.; VALE, F.X.R.; COSTA, H. Controle de Doenças de Plantas - Hortaliças. v.2. Viçosa, UFV, p.445-522, 2000.

JULIATTI, F.C.; OLIVEIRA FILHO, G.M; PEIXOTO, J.R. Resistência de cultivares de cenoura à queima das folhas (Alternaria dauci) no verão, em Uberlândia-MG. Horticultura Brasileira, Resumos, v.14, n.1, 1996.

LOPES, C.A.; RITSCHEL, P.S.; VIEIRA, J.V.; LIMA, D.B. Comportamento de genótipos de cenoura para verão em localidades com diferentes etiologias da queima-das-folhas. Horticultura Brasileira, Brasília, v.18, p.119-122, 2000.

PESSOA, H.B.S; CORDEIRO, C.M.T. Avaliação de cultivares de cenoura no outono-inverno no Distrito Federal. Horticultura Brasileira, Brasília, v.15, n.1, p.72-74, 1997.

SEDIYAMA, M.A.N.; VIDIGAL, S.M.; GARCIA, N.C.P.; PEREIRA, P.R.G. Produção e classificação de cenoura 'Brasília' com adubação orgânica à base de resíduos de suinocultura. Horticultura Brasileira. XXXVI CONGRESSO BRASILEIRO DE OLERICULTURA, Rio de Janeiro-RJ, 22 a 26 de julho de 1996. Resumos. v.14, n.1, maio de 1996.

SOUZA, J.L. Efeito do composto orgânico e da cobertura morta na cultura da cenoura. Horticultura Brasileira. XXXVI CONGRESSO BRASILEIRO DE OLERICULTURA, Rio de Janeiro-RJ, 22 a 26 de julho de 1996. Resumos. v.14, n.1, maio de 1996.

REIFSCHNEIDER, F.J.B. Queima das folhas da cenoura, um complexo patológico. Fitopatologia Brasileira.v.5, p.445-446, 1980.

VIEIRA, J.V.; PESSOA, H.B.S.V. Cultivares. Cultivo da cenoura (Daucus carota L.). Instrução Técnica da Embrapa Hortaliças. n.13. Brasília, dezembro de 1997. 19 p. 